\title{
Avaliação de parasitismo dos inimigos naturais de Sirex noctilio em plantios de Pinus taeda
}

\author{
Parasitism assessment of enemies of natural Sirex noctilio in plantations of Pinus \\ taeda
}

\author{
SILVIO Carolo Junior ${ }^{1}(*)$ \\ Daniele Ukan² \\ Susete do Rocio Chiarello Penteado 3
}

\section{Resumo}

Este trabalho teve como objetivo determinar a dispersão natural e a eficiência dos agentes de controle biológico de Sirex noctilio (Fabricius). O experimento foi instalado no município de Palmas, PR em um plantio de Pinus taeda L (12 anos com densidade de 1051 árvores. $\mathrm{ha}^{-1}$ ), com desbaste misto realizado aos 10 anos de idade. Foram instalados 05 grupos de árvores-armadilha. Cada grupamento foi composto por cinco árvores, as quais foram estressadas artificialmente com a aplicação de herbicida. Posteriormente deuse a inspeção das árvores-armadilha, as árvores atacadas foram seccionadas em toretes de $1 \mathrm{~m}$ de comprimento e armazenadas em tambores divididos em dois tratamentos, com e sem a aplicação do nematóide Deladenus siricidicola (Bedding). Os adultos emergidos foram coletados e armazenados para serem inspecionados a fim de verificarse o parasitismo. A emergência dos indivíduos deu-se a partir da segunda quinzena de novembro até a primeira quinzena de fevereiro. Emergiram 45 adultos de $S$. noctilio, sendo 29 fêmeas e 16 machos. A relação macho: fêmea (M:F) encontrada foi de 0,55:1. A porcentagem total de parasitismo pelo nematóide $D$. siricidicola foi de $37,78 \%$, sendo que nos toretes que não foram aplicados o controle biológico o parasitismo foi de $40 \%$ e 33,33\% nos toretes em que ocorreu a inoculação. Quanto ao parasitismo por Ibalia leucospoides (Hochenwarth) o mesmo foi de $8,16 \%$. O estabelecimento e a dispersão dos inimigos naturais Deladenus siricidicola e Ibalia leucospoides ocorreu na área do estudo.

Palavras-chave: Deladenus siricidicola, Ibalia leucospoides, Controle Biológico.

1 Me.; Ciências Florestais; Universidade Estadual do Centro-Oeste, UNICENTRO, Brasil; Engenheiro Florestal da Reflorasul S.A., Professor Horista da Universidade do Contestado e Professor horísta da Universidade do Contestado; Endereço: Reflorasul S.A.. Rua Sete de Setembro, Divino. CEP: 85555-000 - Palmas, PR - Brasil; E-mail: silviocarolojr@ hotmail.com $\left(^{*}\right)$ Autor para correspondências

2 Dra.; Engenharia Florestal; Universidade Federal do Paraná, UFPR, Brasil; Professora adjunta na Universidade Estadual do Centro-Oeste; Endereço: Universidade Estadual do Centro-Oeste, Departamento de Engenharia Florestal.. PR 153 - Km 7, Riozinho. CEP: 84500000 - Irati, PR - Brasil; E-mail: daniukan@yahoo.com.br

3 Dra.; Ciências Biológicas; Universidade Federal do Paraná, UFPR, Brasil; Pesquisadora da Empresa Brasileira de Pesquisa Agropecuária - Embrapa Florestas; Endereço: Empresa Brasileira de Pesquisa Agropecuária, Centro Nacional de Pesquisa de Florestas. Estada da Ribeira, km 111, Embrapa. CEP: 83411-000 - Curitiba, PR - Brasil; E-mail: susete. penteado@embrapa.br 


\section{Abstract}

This study aimed to determine the natural dispersion and the efficiency of biological control agents Sirex noctilio (Fabricius). The experiment was conducted in the city of Palmas - PR on a plantation of loblolly Pinus taeda L (12 years - 1051 trees.ha $^{-1}$ ), with some thinning 10 year old trees. 05 groups of trees-trap were also installed. Each grouping consisted of five trees which were artificially stressed with the application of herbicide. Upon inspection of the trees-trap, the affected trees were cut into small logs of $1 \mathrm{~m}$ length and stored in drums divided into two treatments with and without the application of nematode Deladenus siricidicola (Bedding). The emerging adults were collected and stored for inspection in order to verify parasitism. The emergence of individuals took place on the second half of november to the first half of february. In total, 45 adults $S$. noctilio emerged, 29 females and 16 males. The relation male:female (M:F) was found to be $0.55: 1$. The overall percentage of parasitism by the nematode D. siricidicola was $37.78 \%$. The small logs that were not applied biological control, $40 \%$ and $33.33 \%$ of parasitism where inoculation occurred. Parasitism by Ibalia leucospoides (Hochenwarth) was $8.16 \%$. The establishment and dispersion of natural enemies Deladenus siricidicola and Ibalia leucospoides occurred in the study area.

Keywords: Deladenus siricidicola, Ibalia leucospoides, Biological Control.

\section{INTRODUÇÃO}

Devido aos incentivos fiscais que ocorreram na década de 60, os reflorestamentos com o Pinus spp. foram intensificados no país, principalmente nos estados do Sul do Brasil devido à adaptação das espécies introduzidas, onde houve a expansão gradativa dos plantios comerciais (EMBRAPA-CNPF, 1988).

As condições de adaptação do gênero Pinus aos solos ligeiramente ácidos, característica preponderante no país, permitiram a implantação de extensas áreas que, juntamente com a adoção de práticas silviculturais adequadas, tornam as espécies do gênero importantes fontes de matériaprima, proveniente de florestas estabelecidas dentro de padrões de sustentabilidade (KRONKA et al., 2005). De acordo com ABRAF (2017) a área de plantios de Pinus no Brasil é de 1,6 milhões de hectares, sendo que o estado do Paraná possui $42 \%$ deste total.

No entanto, quando os plantios florestais são conduzidos sem as técnicas apropriadas de manejo, tornam-se um local suscetível ao ataque de pragas, dentre elas destaca-se a Sirex noctilio (Hymenoptera: Siricidae) conhecida popularmente como vespa-da-madeira a qual é uma praga florestal que vem causando prejuízos econômicos aos plantios de Pinus spp. e ao planejamento florestal desde meados de 1980.

\section{Distribuição geográfica de S. noctilio}

A S. noctilio é originária da Europa, Ásia e Norte da África (IEDE et al., 1988). Na década de 1980 S. noctilio foi registrado na América do Sul, mais precisamente no Uruguai (REBUFFO, 1990). Na Argentina foi detectada, pela primeira, vez em 1985 na província de Entre Ríos, próxima à divisa com o Uruguai e em 1993, na zona de San Carlos de Bariloche, Província de Río 
Negro (KLASMER et al., 2000). Em fevereiro de 1994, no Vale de Calamuchita na Província de Córdoba (SANASA, 2004).

No Brasil, a primeira ocorrência foi no ano de 1988, no estado do Rio Grande do Sul, nos municípios de Gramado, Canela e São Francisco de Paula (IEDE et al., 1988). No ano de 1989 foi registrada a presença desta praga no município de Lages, SC, e em 1994, em Palmas no Paraná, ambas em grupamentos de árvores-armadilha (PENTEADO, 1995). Até o ano de 2004 a S. noctilio ficou restrita aos estados do Sul do país, quando foi então detectada em São Paulo, nos municípios de Jundiaí, Capão Bonito, Itapeva e Itapirapuá Paulista. Em janeiro de 2005 foi detectada em plantios de Pinus patula (Schltdl \& Cham.) em Minas Gerais (IEDE e ZANETTI, 2007).

\section{Classificação Taxonômica, Morfologia e Ciclo Biológico de S. noctilio}

De acordo com Neumann et al. (1987) S. noctilio apresenta a seguinte classificação:

Ordem: Hymenoptera;

Sub-ordem: Symphyta;

Família: Siricidae;

Subfamília: Siricinae;

Gênero Sirex Linnaeus, 1761;

Espécie Sirex noctilio Fabricius, 1793.

De acordo Costa et al. (2014) a S. noctilio desenvolve-se por metamorfose completa (holometabolia), ou seja, possui as fases de ovo, larva, pupa e adulto.

Penteado et al. (2014) relatam que o S. noctilio é atraído para árvores de Pinus estressadas, perfurando o tronco onde deposita seus ovos. Cada fêmea produz em média 226 ovos (CARVALHO, 1992).

Durante a postura, além dos ovos, a fêmea introduz na árvore também os esporos de um fungo simbionte, Amylostereum areolatum (Fries) Boidin e uma mucosecreção. O fungo e o muco, juntos são tóxicos à planta e muitas das árvores atacadas podem apresentar clorose das acículas em torno de 10 a 14 dias após o ataque, sendo que o progresso desta clorose depende da intensidade do ataque e da suscetibilidade da árvore hospedeira (PENTEADO et al., 2002).

Os ovos são brancos, alongados com superfície lisa, colocados a uma profundidade média de 12 mm (EMBRAPA FLORESTAS, 2011). Carvalho (1992) cita que o período de incubação dura em torno de 14 a 28 dias.

Iede et al. (1988) descrevem as larvas como cilíndricas, de coloração esbranquiçada, com três pares de patas torácicas; vestigiais e um pequeno espinho marrom-avermelhado na região supra-anal. As mandíbulas são fortes e de coloração marrom-avermelhada.

$\mathrm{Na}$ fase de pré-pupa, as larvas tendem a se aproximar da região cambial da madeira, onde escavam suas câmaras pupais (COSTA, et al., 2014).

Entre os meses de setembro e outubro, as larvas dão origem às primeiras pupas, que se transformam em adultos a partir do final de outubro (EMBRAPA FLORESTAS, 2011).

As pupas de $S$. noctilio são brancas, do tipo exarata e apresentam um tegumento fino e transparente, tornando-se escurecidas próximo à emergência dos adultos (IEDE e ZANETTI, 2007). Conforme Carvalho (1992) a duração do período pupal varia de 16 a 20 dias. Costal et al., (2011) expõem que os adultos variam de 1 a 3,5 cm de comprimento. 
Segundo Neumann et al. (1987) as fêmeas são de coloração azul metálica, exceto nas asas e pernas onde são âmbar, apresentam um ovipositor protegido por uma bainha, projetado cerca de 2 a $3 \mathrm{~mm}$ para fora do abdômen, possuem pernas delgadas e antenas maiores que a dos machos. Os autores ainda descrevem que o macho apresenta tórax azul metálico com segmentos abdominais marrom alaranjados e as pernas anteriores e médias delgadas e as posteriores robustas para facilitar a cópula.

$\mathrm{Na}$ fase adulta, os insetos não se alimentam e são totalmente dependentes das reservas de gordura do corpo (MADDEN, 1974).

Após a emergência, os machos se aglomeram ao redor da copa, no topo das árvores. As fêmeas dirigem-se a estas aglomerações e o acasalamento ocorre nos galhos superiores. A reprodução de S. noctilio pode ser sexuada ou assexuada, sendo que da última só originam-se machos (partenogênese arrenótoca) (MORGAN, 1968 citado por GAIAD 2001).

A proporção macho:fêmea varia de 1,5:1 a 16,5:1, sendo que os machos emergem uma semana antes das fêmeas (TAYLOR, 1981).

De acordo com Penteado (1995) a maioria das larvas concentram-se do terço médio ao terço superior da árvore.

No Brasil, esta praga normalmente tem ciclo de um ano, sendo que os adultos voam no período de outubro a meados de janeiro, com picos populacionais entre novembro e dezembro (EMBRAPA FLORESTAS, 2011).

Em árvores muito estressadas ou quando o ataque ocorre em uma bifurcação, pode ocorrer um ciclo curto, com duração de 3 a 4 meses (PENTEADO et al., 2002).

Penteado et al. (2002) descrevem que a vespa-da-madeira é atraída preferencialmente por árvores estressadas, que apresentam as condições ideais para o desenvolvimento das suas larvas. Os autores ressaltam que as árvores preferidas são aquelas que apresentam menor diâmetro e encontram-se no estrato das dominadas, embora as árvores dominantes possam também ser atacadas. Para Ribas Junior (1993) as árvores mais susceptíveis ao ataque de Sirex noctilio geralmente têm mais de 12 anos de idade e estão fisiologicamente estressadas.

O principal dano é provocado na ocasião da postura, onde a ação do fungo e do muco desencadeia uma série de reações na árvore, culminando em sua morte. Além disso, a madeira atacada torna-se imprópria para o uso comercial (PENTEADO et al., 2002).

De acordo com Embrapa Florestas (2011) os principais danos provenientes do ataque da $S$. noctilio são as galerias causadas pelas larvas que se desenvolvem no interior da madeira, as manchas azuladas ocasionadas por fungos oportunistas do gênero Botryodiplodia e os orifícios de emergência, provocados pelos insetos adultos que perfuram a madeira para sua emergência.

Após a morte da árvore, a madeira se degrada rapidamente e sua utilização deve ser feita no máximo até seis meses após ter sido atacada (GAIAD, 2001). De acordo com Costa et al. (2011) os sintomas de ataque começam a aparecer logo após os picos populacionais do inseto, sendo mais visíveis após a revoada, a partir do mês de novembro.

\section{Medidas de prevenção da vespa-da-madeira}

De acordo com Embrapa Florestas (2011) as medidas de prevenção são as seguintes: 
Realizar desbastes, adotar medidas de sanidade florestal, eliminando-se restos de desbastes com diâmetro superior a $5 \mathrm{~cm}$, evitar a realização da poda, pelo menos dois meses antes e durante o período de vôo do inseto, não transportar a madeira atacada para áreas sem a presença do inseto.

Ainda segundo Penteado et. al. (2002) deve-se:

Evitar o plantio em áreas com declive acentuado (acima de $25^{\circ}$ ), onde torna-se difícil a realização de tratos silviculturais, principalmente desbastes;

Intensificar o manejo em sítios com baixa produtividade, com solos rasos e pedregosos;

Treinar empregados rurais, de serrarias e de transporte de madeira para identificação da larva e adulto de $S$. noctilio;

Utilizar medidas de prevenção detecção e controle de incêndios florestais.

\section{Monitoramento de S. noctilio}

A definição da área atacada e o monitoramento da dispersão da vespa-da-madeira são atividades essenciais em um programa de controle deste inseto. Isto pode ser determinado pela instalação de árvores-armadilha ou pela realização da amostragem sequencial (PENTEADO et al., 2002).

Para que uma árvore funcione como armadilha, ela deverá ser estressada lentamente, tornando-se atrativa à vespa-da-madeira, o que poderá ser feito pela aplicação de herbicida (PENTEADO et al., 2002). O monitoramento com o uso de árvores-armadilha deve ser realizado anualmente para a detecção precoce do inseto (EMBRAPA FLORESTAS, 2011). As árvoresarmadilha são locais que permitem a imediata introdução de inimigos naturais, para que se reestabeleça o equilíbrio populacional (RODIGHERI et al., 2006). Para a instalação e inspeção das árvores-armadilha deve-se seguir as recomendações de Penteado et al., (2002).

A amostragem sequencial é dimensionada em função dos níveis de ataque. Deve-se realizar uma amostragem por talhão de até 40 ha, avaliando-se, no máximo, 40 árvores por linha, intercalando 8 linhas antes de passar para a próxima linha a ser avaliada e assim sucessivamente até o final da amostragem (PENTEADO et al., 2002). Tratando-se de talhões heterogêneos devem-se realizar no mínimo duas amostragens na mesma área, abrangendo a maior área possível para aumentar a eficiência deste método. Vale ressaltar que o principio deste método é o número de árvores amostradas, portanto, a forma de caminhamento e a disposição das unidades amostrais devem adequar-se ao tamanho e condições do talhão (PENTEADO et al., 2015).

A Tabela 1 demonstra o número de árvores a serem avaliadas em função da porcentagem de ataque.

Quando a porcentagem de ataque encontrada na amostragem sequencial for inferior a $1 \%$ deve-se utilizar as árvores-armadilha para o monitoramento de $S$. noctilio. Inicia-se a amostragem sequencial amostrando um mínimo de 68 árvores e comparar o número de árvores atacadas encontradas na amostra com o número de árvores atacadas apresentado na terceira coluna da tabela, neste caso 34. Se o número de árvores atacadas da amostra for igual ou superior a 34, considerar a amostra completada. Caso este número for inferior a 34, continuar o processo, amostrando mais seis árvores, totalizando 74 árvores amostradas, se o número de árvores atacadas for 36 ou mais, considerar a amostra completada, se este número for inferior a 36, deve-se continuar, até que seja obtido o número mínimo de árvores atacadas requerido na terceira coluna da tabela. 
Quando se atinge 272 árvores amostradas, deve-se interromper a amostragem (EMBRAPA FLORESTAS, 2005).

\section{Tabela 1. Amostragem sequencial.}

\begin{tabular}{|c|c|c|}
\hline \multicolumn{3}{|c|}{ Tabela de Amostragem Sequencial } \\
\hline \multirow{2}{*}{$\begin{array}{l}\text { Número de árvores } \\
\text { amostradas }\end{array}$} & \multicolumn{2}{|c|}{ Número de árvores atacadas } \\
\hline & Atacadas da amostra & $\begin{array}{c}\text { Mínimo para interromper a } \\
\text { amostragem }\end{array}$ \\
\hline 68 & & 34 \\
\hline 74 & & 36 \\
\hline 80 & & 37 \\
\hline 87 & & 38 \\
\hline 94 & & 39 \\
\hline 102 & & 41 \\
\hline 111 & & 42 \\
\hline 121 & & 44 \\
\hline 132 & & 45 \\
\hline 145 & & 46 \\
\hline 159 & & 48 \\
\hline 175 & & 49 \\
\hline 194 & & 50 \\
\hline 215 & & 52 \\
\hline 241 & & 53 \\
\hline 272 & & 54 \\
\hline 272 & & $*$ \\
\hline
\end{tabular}

* Interromper a amostragem, independente do número de árvores atacadas encontradas na amostra. Fonte: Adaptado Embrapa Florestas, 2005.

\section{Métodos de controle de S. noctilio}

Face ao caráter oportunista da praga, a adoção de práticas silviculturais adequadas para manter a sanidade e o vigor dos plantios de Pinus é o princípio fundamental para prevenir ataques severos (IEDE et al., 2009).

A prevenção de $S$. noctilio dar-se através do controle silvicultural onde desbastes ocasionais e seletivos são executados para impedir a distribuição desta praga, pois povoamentos bem conduzidos e bem manejados não sofrem perdas econômicas (COSTA et al., 2014).

Outro sistema de controle que apresenta resultados satisfatórios é o controle biológico, o qual é realizado por meio do nematóide Deladenus siricidicola (Tylenchidae: Neotylenchidae) e da Ibalia leucospoides (Hymenoptera: Ibalidae).

O agente de controle biológico mais importante para o controle da vespa-da-madeira é o nematóide Deladenus siricidicola, o qual foi introduzido no Brasil e é criado na Embrapa Florestas, contando com o apoio do Fundo Nacional de Controle à Vespa-da-Madeira - FUNCEMA (IEDE et al., 2009).

Como o nematóide alimenta-se do mesmo fungo que a larva de $S$. noctilio, inevitavelmente, estes se encontram e o nematóide, até então de vida livre, torna-se de vida parasitária, penetrando 
na larva. A larva parasitada pelo nematóide continua a se desenvolver normalmente até a fase adulta (COSTA et al., 2011).

O nematóide é produzido, anualmente, no período de março a agosto, e enviado aos proprietários de plantios de Pinus atacados pela vespa-da-madeira na forma de doses de $20 \mathrm{~mL}$, contendo, cada uma, cerca de um milhão de nematóides. Cada dose é suficiente para a inoculação de 10 árvores, em média, sendo que, em cada árvore são inoculados em torno de 100.000 nematóides (PENTEADO et al., 2014).

Para aplicar o nematóide em árvores atacadas pela vespa-da-madeira é necessário misturálo a uma gelatina para mantê-los hidratados até que penetrem nas árvores. Para isso, deve-se dissolver $30 \mathrm{~g}$ de gelatina em pó, sem sabor, em uma pequena quantidade de água quente, adicionar $100 \mathrm{~mL}$ de água fervendo e, em batedeira, na velocidade média, misturar a gelatina até ficar completamente dissolvido, em seguida adicionar $200 \mathrm{~mL}$ de água gelada à gelatina dissolvida, bater na batedeira até a solução atingir uma consistência cremosa, deve-se colocar uma dose de nematóides e continuar batendo até que a mesma esteja bem distribuída. Despejar o inóculo dentro de um saco plástico e depois acondicioná-lo em uma caixa de isopor para levá-lo a campo (PENTEADO et al., 2002).

Penteado et al. (2014) ainda realizaram uma pesquisa com a finalidade de desenvolver uma nova tecnologia para a substituição da gelatina por outro espessante, o qual deveria ter como característica o fácil preparo, para otimização do processo de inoculação e que assegurasse a padronização da atividade. O hidrogel foi a alternativa que apresentou o melhor resultado em laboratório, por ter o menor custo, não afetar a sobrevivência do nematóide e ter maior estabilidade quando armazenado em geladeira.

Outro agente de controle da vespa-da-madeira é a Ibalia leucospoides que é um parasitóide de ovos e larvas de primeiro e segundo instar, com níveis de parasitismo de cerca de 25\% (IEDE et al., 2009).

Antes de iniciar a postura, a fêmea de I. leucospoides realiza uma inspeção na casca da árvore, com o auxílio de suas antenas. Quando encontra um local adequado introduz as antenas dentro do orifício de postura de $S$. noctilio e inspeciona os túneis realizados pela fêmea de seu hospedeiro. Para a postura propriamente dita, a fêmea abaixa o sétimo par de esternitos abdominais (hipopígio), introduzindo-o nas fissuras existentes na casca da árvore, realizando movimentos ritmados, para cima e para baixo, para a deposição dos ovos (CHRYSTAL, 1930 citado por PENTEADO, 1995).

$\mathrm{O}$ ovo de I. leucospoides é pedunculado. Depois de depositado no corpo da larva do hospedeiro, aumenta de 3 a 8 vezes em ambas as dimensões. É depositado no ovo do hospedeiro ou durante o primeiro instar larval (CARVALHO, 1992).

I. leucospoides passa por quatro estágios de desenvolvimento larval, sendo que três deles são dentro das larvas da vespa e o último externamente. Nesta fase permanecem nas galerias construídas pelas larvas da vespa-da-madeira, quando irão empupar, próximo à casca e emergir, normalmente, um ano após postura (PENTEADO et al., 2002).

O período de emergência dos adultos ocorre entre os meses de novembro e janeiro e entre abril e maio (CARVALHO, 1992).

Quando o controle silvicultural e o controle biológico são efetuados simultaneamente tem-se um dos melhores programas de manejo integrado de pragas. Diante do exposto, este trabalho teve por objetivo determinar a dispersão natural e a eficiência dos agentes de controle biológico de Sirex noctilio. 


\section{MATERIAL E MÉTODOS}

O presente estudo foi realizado no município de Palmas, localizado no Sudoeste do estado do Paraná, a uma latitude 26029'03”S e a uma longitude 51'59'26”W, com altitudes variando entre 950 a $1356 \mathrm{~m}$. A temperatura média anual é de $16^{\circ} \mathrm{C}$. O clima da região segundo a classificação de Köppen é Cfb. A área de estudo possui 305 ha, com 112 ha cultivados com P. taeda com 12 anos de idade e densidade inicial de 1600 árvores por hectare (espaçamento 2,5 x 2,5). Foi efetuado um desbaste (misto) em função do número de indivíduos do povoamento aos 10 anos de idade, retirando-se 33\% das árvores, ou seja, a sexta fileira no desbaste sistemático, enquanto que no desbaste seletivo 20\% das árvores remanescentes foram retiradas entre as linhas desbastadas.

Para determinar a dispersão natural e a eficiência dos agentes de controle biológico de S. noctilio, foram instalados grupos de árvores-armadilha (Figura 1) em setembro de 2012, na disposição de um grupo para cada 25 ha de plantio de Pinus taeda L, totalizando 5 grupamentos de árvores armadilhas contendo cinco árvores cada. $\mathrm{O}$ estressamento das árvores-armadilha deuse através da utilização do herbicida 2,4-D amina + picloran, a uma concentração de $20 \%$, sendo que as árvores selecionadas para compor o grupo de árvores-armadilha apresentavam alguma deformidade ou encontravam-se no estrato das dominadas. A inspeção das árvores-armadilha foi realizada em junho de 2013, onde as árvores foram derrubadas com motosserra e traçadas do terço médio ao terço superior do tronco, retirando-se de dois a três toretes por árvore com aproximadamente $30 \mathrm{~cm}$ de comprimento cada, para verificar se haviam sintomas de ataque de S. noctilio.

\section{Figura 1. Grupo de árvores-armadilha utilizado para o monitoramento de S. noctilio.}

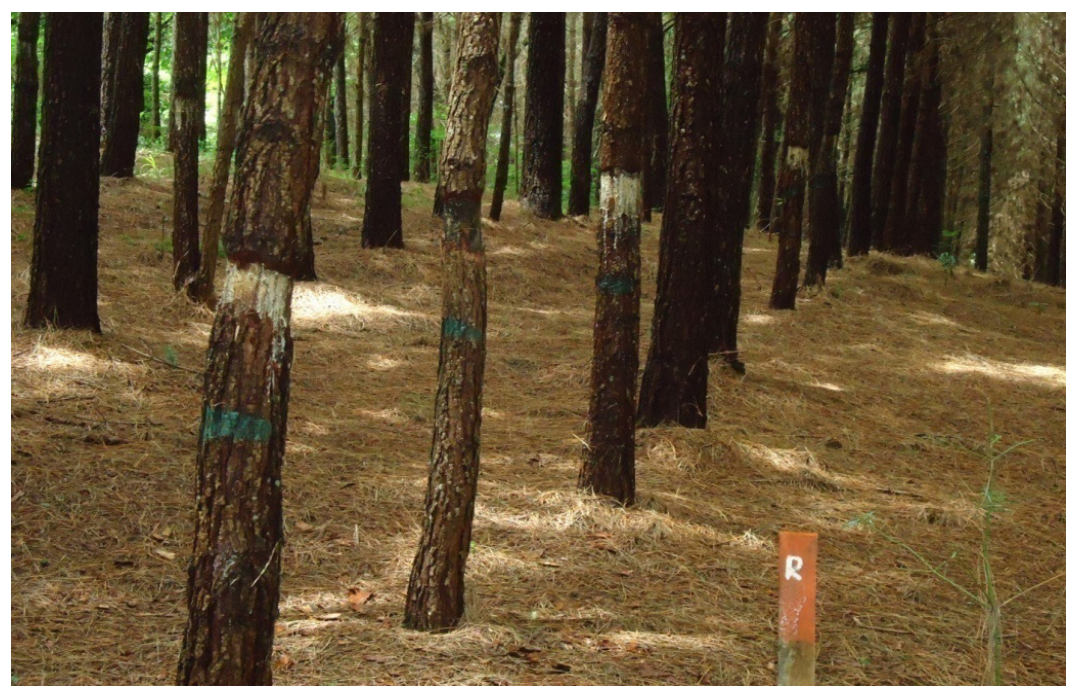

Fonte: Autores (2012).

No preparo das amostras para realizar a avaliação do parasitismo dos inimigos naturais da S. noctilio, foram selecionadas cinco árvores, dentre os grupamentos de árvores-armadilha, com a presença de sintomas de ataque, sendo que as mesmas foram seccionadas em toretes de $1 \mathrm{~m}$ de comprimento. Cada árvore gerou 10 toretes, sendo que a aplicação do inóculo com Deladenus siricidicola deu-se de forma alternada, partindo-se da base da árvore, desta forma, o primeiro, o terceiro, o quinto, o sétimo e o nono torete não receberam o inóculo, consequentemente os 
demais receberam o tratamento, sendo que em cada torete que recebeu o tratamento foi efetuada três perfurações com o auxilio do martelo aplicador (Figura 2), com $30 \mathrm{~cm}$ de distância entre os orifícios onde foi aplicado o inóculo.

\section{Figura 2. Martelo de aplicação utilizado para abertura de orifício}

Fonte: Autores (2013)

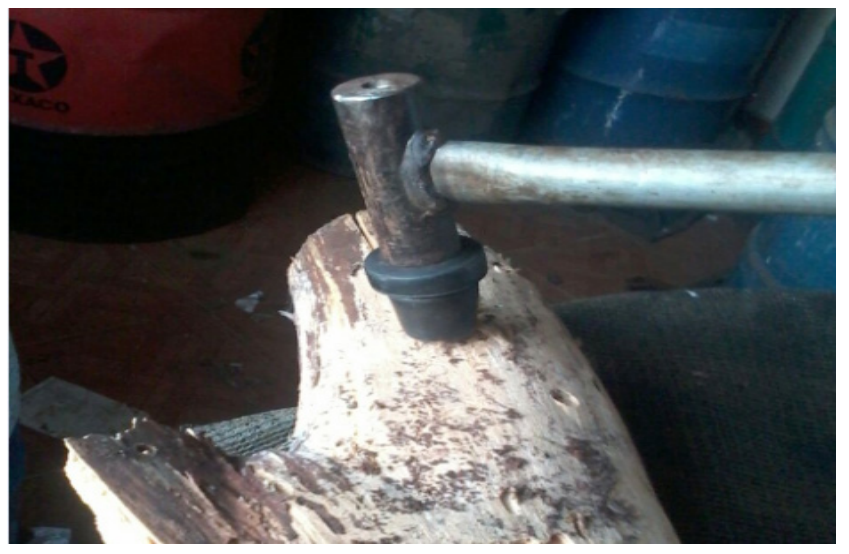

O preparo do inóculo seguiu as recomendações supracitadas de Penteado et al. (2002). Estes toretes foram levados do campo para uma sala, onde foram armazenados em tambores cobertos com sombrite e divididos em dois tratamentos: 1) com inoculação de $D$. siricidicola e; 2) sem a inoculação de $D$. siricidicola. Cada dois tambores correspondiam a uma árvore (Figura 3), sendo que um continha cinco toretes com nematoides inoculados e os outros cinco sem inoculação. Com este processo pretendeu-se identificar se o controle biológico está ocorrendo naturalmente através da avaliação de parasitismo nas árvores não inoculadas com o nematóide $D$. siricidicola.

\section{Figura 3. Tambores de armazenamento dos toretes cobertos com sombrite.}

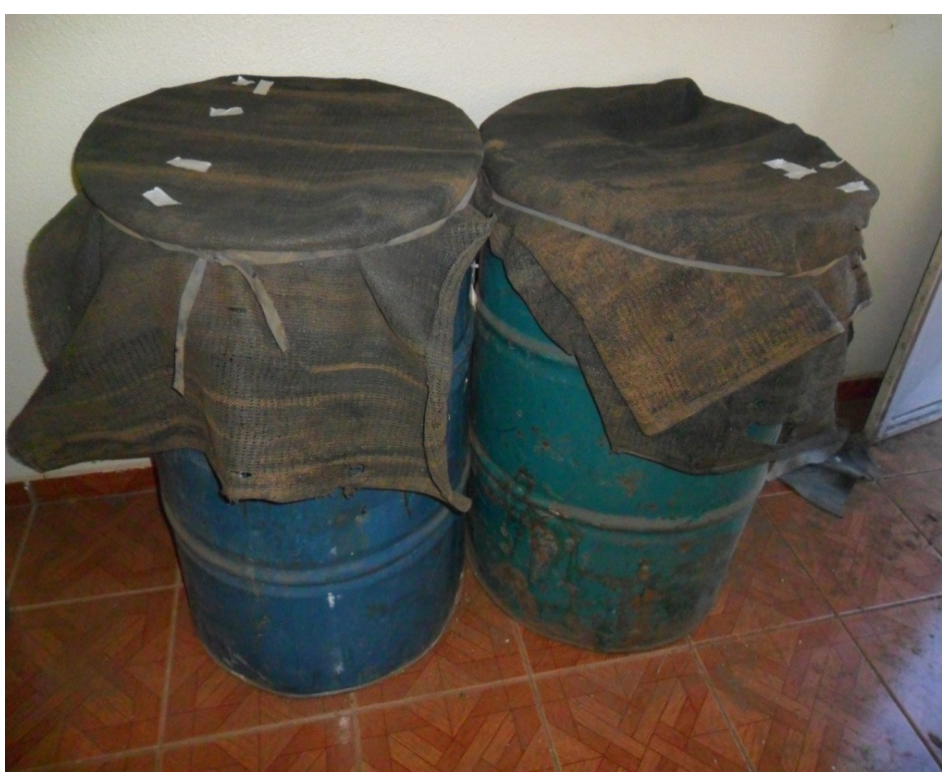

Fonte: Autores (2013). 
Após a emergência dos adultos da vespa-da-madeira nos tambores, os mesmos foram coletados e armazenados em frascos contendo álcool $70 \%$ para posteriormente serem avaliados. A avaliação dos adultos de S. noctilio foi realizada no laboratório de Entomologia da Universidade do Contestado (UnC) Canoinhas, Santa Catarina. Para tanto, os insetos foram acondicionados em placas de Petri para posterior observação em uma lupa com aumento de 40 vezes, onde separou-se o abdômen do tórax com pinças entomológicas, verificando-se a presença do nematóide. Tanto as fêmeas como os machos de S. noctilio passaram por este procedimento.

A determinação da porcentagem de parasitismo foi obtida pela fórmula 01 abaixo (PENTEADO et al., 2002):

$$
\% \text { de parasitismo }=\frac{n^{\circ} \text { de adultos de } S . \text { noctilio parasitados }}{n^{\circ} \text { total de adultos de } S . \text { noctilio }} \quad X 100
$$

Os adultos de I. leucospoides emergiram dos mesmos toretes e das mesmas gaiolas onde estavam acondicionados os adultos de S. noctilio. Os indivíduos de I. leucospoides foram coletados, contados, separados por sexo e liberados novamente na fazenda.

O calculo da porcentagem de parasitismo deu-se pela fórmula 02 sugerida por Penteado et al. (2002):

$\%$ de parasitismo $=$ $\mathrm{n}^{\circ}$ de adultos do parasitóide X 100 $\mathrm{n}^{\circ}$ total de adultos de $S$. noctilio + $\mathrm{n}^{\circ}$ do parasitóide

\section{RESULTADOS E DISCUSSÕES}

Verificou-se o ataque da vespa-da-madeira em todos os grupamentos instalados, variando entre uma a duas árvores atacadas por grupamento, representando $28 \%$ das árvores-armadilha atacadas.

A emergência dos adultos de S. noctilio das amostras ocorreu entre a segunda quinzena de novembro e a primeira quinzena de fevereiro, coincidindo com o período de emergência dos adultos proposto pela literatura (EMBRAPA FLORESTAS, 2011). Na Tabela 2, estão descritos o número de adultos emergidos de $S$. noctilio das árvores-armadilha, durante o período de novembro de 2013 a fevereiro de 2014. 
Tabela 2. Adultos de Sirex noctilio que emergiram de toretes coletados de árvores-armadilha inoculados e não inoculados com Deladenus siricidicola. Novembro de 2013 a fevereiro de 2014, município de Palmas, PR.

\begin{tabular}{|c|c|c|c|c|c|c|c|c|c|c|c|c|c|c|c|c|c|c|c|c|c|c|}
\hline \multirow{2}{*}{ CÓDIGO } & \multicolumn{2}{|c|}{$21 / \mathrm{Nov}$} & \multicolumn{2}{|c|}{$28 /$ nov } & \multicolumn{2}{|c|}{$03 / \mathrm{dez}$} & \multicolumn{2}{|c|}{$09 / \mathrm{dez}$} & \multicolumn{2}{|c|}{$13 / \mathrm{dez}$} & \multicolumn{2}{|c|}{$17 / \mathrm{dez}$} & \multicolumn{2}{|c|}{$30 / \mathrm{dez}$} & \multicolumn{2}{|c|}{ 06/jan } & \multicolumn{2}{|c|}{$15 /$ jan } & \multicolumn{2}{|c|}{ 30/jan } & \multicolumn{2}{|c|}{$06 /$ fev } \\
\hline & $\mathrm{F}$ & $\mathrm{M}$ & $\mathrm{F}$ & $\mathrm{M}$ & $\mathrm{F}$ & $\mathrm{M}$ & $\mathrm{F}$ & $\mathrm{M}$ & $\mathrm{F}$ & $\mathrm{M}$ & $\mathrm{F}$ & $M$ & $\mathrm{~F}$ & $\mathrm{M}$ & $\mathrm{F}$ & $\mathrm{M}$ & $\mathrm{F}$ & $\mathrm{M}$ & $\mathrm{F}$ & $\mathrm{M}$ & $\mathrm{F}$ & $\mathrm{M}$ \\
\hline TCN 1 & 0 & 0 & 0 & 0 & 4 & 1 & 5 & 1 & 0 & 0 & 0 & 0 & 0 & 0 & 0 & 0 & 0 & 0 & 2 & 1 & 0 & 0 \\
\hline TSN 1 & 0 & 0 & 4 & 3 & 0 & 0 & 9 & 3 & 1 & 1 & 1 & 1 & 0 & 0 & 0 & 1 & 1 & 1 & 0 & 0 & 0 & 0 \\
\hline TCN 2 & 0 & 0 & 0 & 0 & 0 & 0 & 0 & 0 & 0 & 0 & 0 & 0 & 0 & 0 & 0 & 0 & 0 & 0 & 0 & 0 & 0 & 0 \\
\hline TSN 2 & 0 & 0 & 0 & 0 & 0 & 0 & 0 & 0 & 0 & 0 & 0 & 0 & 0 & 0 & 0 & 0 & 0 & 0 & 0 & 0 & 0 & 0 \\
\hline TCN 3 & 0 & 0 & 0 & 0 & 0 & 0 & 0 & 0 & 0 & 0 & 0 & 0 & 0 & 0 & 0 & 0 & 0 & 0 & 0 & 0 & 0 & 0 \\
\hline TSN 3 & 0 & 0 & 1 & 0 & 0 & 0 & 0 & 0 & 0 & 0 & 0 & 0 & 0 & 0 & 0 & 0 & 0 & 0 & 0 & 0 & 0 & 0 \\
\hline TCN 4 & 0 & 0 & 0 & 0 & 0 & 0 & 0 & 0 & 0 & 0 & 0 & 0 & 0 & 0 & 0 & 0 & 0 & 0 & 0 & 0 & 0 & 0 \\
\hline TSN 4 & 1 & 0 & 0 & 0 & 0 & 0 & 0 & 0 & 0 & 0 & 0 & 0 & 0 & 0 & 0 & 0 & 0 & 0 & 0 & 0 & 0 & 0 \\
\hline TCN 5 & 0 & 0 & 0 & 0 & 0 & 0 & 0 & 0 & 0 & 0 & 0 & 0 & 0 & 0 & 0 & 0 & 0 & 0 & 0 & 0 & 0 & 1 \\
\hline TSN 5 & 0 & 1 & 0 & 0 & 0 & 0 & 0 & 0 & 0 & 0 & 0 & 0 & 0 & 1 & 0 & 0 & 0 & 0 & 0 & 0 & 0 & 0 \\
\hline
\end{tabular}

Em que: T - Tambor; $\mathrm{CN}$ - torete inoculado com o nematóide; $S N$ - torete não inoculado com o nematóide; $F$ fêmea da vespa-da-madeira; $M$ - macho da vespa-da-madeira.

Das 5 árvores avaliadas, emergiram 45 adultos de $S$. noctilio, sendo 29 fêmeas e 16 machos. A relação macho:fêmea (M:F) encontrada foi de 0,55:1, divergindo dos valores de 1,5:1 relatado pela EMBRAPA Florestas (2005). Este fato pode ser explicado devido ao baixo número de insetos emergidos, quando comparados com Taylor (1981), em que a relação M:F variou de 1,5:1 até 16,5:1. Batista (2014) encontrou uma relação M:F de 1,91:1 no município de Telêmaco Borba, PR, no período de outubro de 2013 a fevereiro de 2014.

O período de maior emergência dos adultos de $S$. noctilio ocorreu no mês de dezembro (20 fêmeas e 8 machos) seguido pelos meses de novembro (6 fêmeas e 4 machos), janeiro (3 fêmeas e 3 machos) e fevereiro (0 fêmea e 1 macho), Figura 4. Estes dados confirmam a citação de Penteado et al. (2002), que citam que no Brasil os insetos adultos emergem no período de novembro a abril, com picos populacionais nos meses de novembro e dezembro.

Figura 4. Emergência dos adultos de $S$. noctilio em plantios de Pinus taeda. Novembro de 2013 a fevereiro de 2014, Palmas - PR.

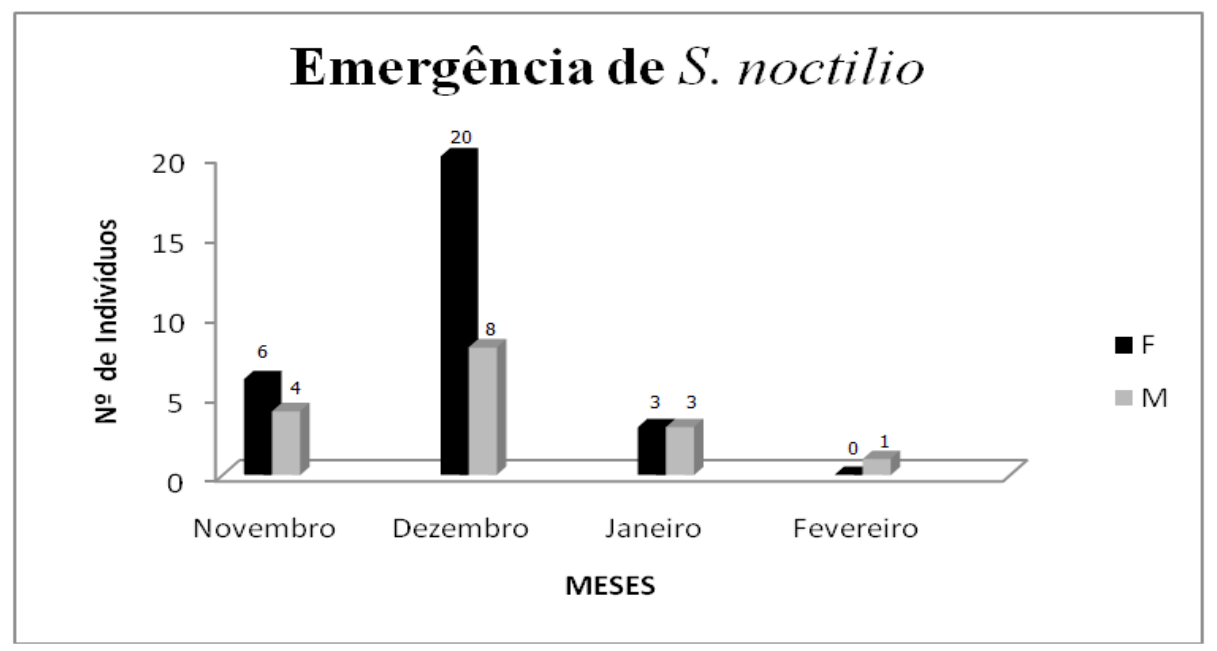

Fonte: Autores (2015).

JUNIOR, S. C. et al. 
Tendo em vista que a inspeção das árvores-armadilha aconteceu somente no mês de junho, não foi possível verificar neste estudo se houve indivíduos que se desenvolveram em um ciclo curto, ou seja, adultos de $S$. noctilio que emergiram nos meses de março e abril conforme especificado por Iede et al. (1998). Nota-se que a emergência dos adultos de $S$. noctilio foi significativamente superior nos meses de novembro e dezembro em relação aos meses de janeiro e fevereiro. $\mathrm{O}$ conhecimento do período de emergência deste inseto auxilia na programação e no planejamento das ações de monitoramento e controle.

Do total de 45 adultos emergidos, $11,11 \%$ eram machos e $26,67 \%$ fêmeas parasitadas (Tabela 3).

Tabela 3. Adultos de S. noctilio que emergiram dos toretes das árvoresarmadilha inoculados e não inoculados com o nematóide e porcentagem de parasitismo, município de Palmas, PR.

\begin{tabular}{cccc}
\hline & $\begin{array}{c}\text { Número de } \\
\text { individuos }\end{array}$ & $\begin{array}{c}\text { No de indivíduos } \\
\text { parasitados }\end{array}$ & Total (\%) \\
\hline Machos & 16 & 12 & 26,67 \\
Fêmeas & 29 & 5 & 11,11 \\
Total & 45 & 17 & 37,78 \\
\hline
\end{tabular}

Considerando a variável parasitismo, Penteado (1995) relatou que 71,79\% e 26,59\% dos adultos de $S$. noctilio encontravam-se parasitados pelo nematóide $D$. siricidicola nos município de Encruzilhada do Sul, RS e Lages, SC, respectivamente. Iede e Zanetti (2007) referenciam que o controle biológico com o nematóide $D$. siricidicola, pode alcançar níveis de parasitismo próximos a $100 \%$.

Na Tabela 4 encontra-se o número de indivíduos adultos de $S$. noctilio emergidos, parasitados ou não, separados por tratamentos (toretes inoculados e não inoculados).

\section{Tabela 4. Número de adultos de $S$. noctilio emergidos nos toretes inoculados e não-inoculados.}

\begin{tabular}{ccc}
\hline & Toretes inoculados & Toretes não inoculados \\
\hline Machos de $S$. noctilio parasitados & 1 & 4 \\
Machos de $S$. noctilio não parasitados & 3 & 8 \\
Fêmeas de S. noctilio parasitados & 4 & 8 \\
Fêmeas de $S$. noctilio não parasitadas & 7 & 10 \\
\hline Parasitismo por nematóide & $33,33 \%$ & $40 \%$ \\
\hline
\end{tabular}

Separando os tratamentos dos toretes onde houve a inoculação de D. siricidicola, obteve-se $33,33 \%$ do total de adultos parasitados, sendo 6,67\% machos e 26,66\% fêmeas. Nos toretes em que não se aplicou o nematóide, a porcentagem de parasitismo foi de 40\%, dos quais 13,33\% e 26,67\% eram machos e fêmeas parasitados, respectivamente (Tabela 4).

O parasitismo apresentou-se maior nos toretes sem a aplicação do nematóide, indicando que a dispersão natural do nematóide está ocorrendo através da vespa-da-madeira na área, o que aumenta a efetividade do controle. Todavia, faz-se necessário dar continuidade à inoculação a fim de alcançar um parasitismo superior a 40\% que é tido como ideal segundo (IEDE et al., 2009). 
Nota-se que a chance do controle biológico se disseminar amplia-se proporcionalmente ao número de fêmeas parasitadas, uma vez que quanto mais fêmeas infectadas, maior será a disseminação do nematóide, tendo em vista que os machos infectados não disseminam o nematóide.

O controle biológico com $D$. siricidicola vem sendo realizado desde 2009, fato este que levou a redução na população da vespa-da-madeira como na disseminação do nematóide, pois como a inoculação ocorreu em anos anteriores, à população da vespa-da-madeira diminuiu, consequentemente, a população do nematóide também sofreu um decréscimo, fator que pode ter influenciado a baixa porcentagem de parasitismo, pois, segundo Batista (2014) a relação densidade-dependente entre parasito e hospedeiro pode explicar o baixo parasitismo pelo nematóide, devendo-se levar em conta a flutuação populacional da praga e seus inimigos naturais. Ainda Rodigheri et al. (2006) relataram que a relação entre $D$. siricidicola e $S$. noctilio, é de parasitismo, ou seja, necessita-se de uma dependência entre o nematóide e seu hospedeiro (a vespa-da-madeira), à medida que há um colapso na população de $S$. noctilio, diminui-se também o parasitismo.

Além disso, a técnica de inoculação, o teor de umidade da madeira e a incompatibilidade entre as populações específicas de $S$. noctilio, $A$. areolatum e $D$. siricidicola podem influenciar o sucesso da inoculação e portanto, a eficácia do $D$. siricidicola como agente de controle biológico ( HURLEY et al., 2007).

A emergência dos adultos de I. leucospoides ocorreu nos meses de dezembro de 2013 e janeiro de 2014, advindos das mesmas gaiolas em que emergiram os adultos de $S$. noctilio. O pico populacional aconteceu no mês de dezembro.

O nível de parasitismo por Ibalia leucospoides foi de 8,16\%, com uma proporção macho: fêmea de 1:1. Este valor é considerado satisfatório, considerando-se que este inimigo tem ocorrência natural e tomando-se como base o trabalho de Penteado (1995) que relata que no ano de 1991 no município de Encruzilhada do Sul, RS, o nível de parasitismo foi de 18,82\%, enquanto que no município de Lages, SC, no ano de 1992 a porcentagem de parasitismo por I. leucospoides foi de $3,97 \%$.

De acordo com Hurley et al. (2007) fatores como a densidade populacional de S. noctilio, sincronia entre $I$. leucospoides e o ciclo de vida da $S$. noctilio, a proporção macho:fêmea do parasita, bem como, a capacidade de adaptação influenciado pela diversidade genética, poderiam influenciar o estabelecimento da I. leucospoides.

Todavia, tanto o nematóide $D$. siricidicola como a população de $I$. leucospoides são dependentes da população da vespa-da-madeira, ou seja, se a população do hospedeiro está em colapso, provavelmente a população do parasitóide também esteja.

\section{CONCLUSÃO}

O controle biológico é um componente essencial no manejo integrado de pragas, principalmente em áreas silviculturais. Pode-se afirmar que na área do estudo está ocorrendo à dispersão natural do $D$. siricidicola, bem como do parasitóide I. leucospoides, tendo em vista que nos toretes onde não houve a inoculação com o patógeno, a porcentagem de parasitismo foi superior 
aos que foram inoculados, indicando que os mesmos estão em processo de estabelecimento no local do estudo.

No entanto, ainda faz-se necessário dar continuidade com o controle biológico nos anos subsequentes, uma vez que a porcentagem de parasitismo não ultrapassou o valor de $40 \%$ que é o recomendado pela Embrapa Florestas.

\section{REFERÊNCIAS}

BATISTA, E.S.de P. Sirex noctilio (Hymenoptera: Siricidae) e seus inimigos naturais em Pinus taeda e caracterização morfológica de Deladenus siricidicola. 2014. 83p. Tese (Doutorado em Agronomia) - Entomologia Agrícola, Universidade Estadual Paulista, Jaboticabal, SP.

CARVALHO, A. G. de. Bioecologia de Sirex noctilio Fabricius, 1793 (Hymenoptera:Siricidae) em povoamentos de Pinus taeda L. 1992. 127 f. Tese (Doutorado em Ciências Florestais) - Setor de Ciências Agrárias, Universidade Federal do Paraná, Curitiba. PR.

COSTA, E.C.; D’AVILA, M.; CANTARELLI, E. B.; MURARI A. B. Entomologia Florestal. 3a ed. Santa Maria: UFSM, 2014. 256p.

COSTA, E.C.; D'AVILA, M.; CANTARELLI, E. B.; MURARI A. B. Entomologia Florestal. $3^{\mathrm{a}}$ ed. Santa Maria: UFSM, 2014. 256p.

EMBRAPA-CNPF.Zoneamento ecológico para plantios florestais no Estado de Santa

Catarina. Documentos, 21. Curitba-PR.1988.

EMBRAPA FLORESTAS. Vespa-da-madeira amostragem sequencial: o primeiro passo para o controle da praga. Colombo, 2005. 1 fôlder.

EMBRAPA FLORESTAS. Vespa-da-madeira. Colombo, 2011. 1 fôlder.

GAIAD, D. C. M. Efeito de desbastes em povoamentos de Pinus taeda na ocorrência da vespa-da-madeira, Sirex noctilio F., 1972. 2001. 97 f. Dissertação (Mestrado em Engenharia Florestal) - Setor de Ciências Agrárias, Universidade Federal do Paraná, Curitiba. PR.

HURLEY, B. P.; SLIPPERS, B.; WINGFIELD, M. J. A comparison of control results for the alien invasive woodwasp, Sirex noctilio, in the southern hemisphere. Agricultural and Forest Entomology, n. 9, p. 159-171. 2007.

IBÁ - Indústria Brasileira de Árvores. Relatório IBÁ 2017. São Paulo. 2017.

IEDE, E.T.; PENTEADO, S. do R. C.; BISOL, J.C. Primeiro registro de ataque de 
Sirex noctilio em Pinus taeda no Brasil. Colombo: EMBRAPA - CNPF, 1988. 12p. (EMBRAPA - CNPF, Circular Técnica, 20).

IEDE, E.T.; ZANETTI, R. Ocorrência e recomendações para o manejo de Sirex noctilio Fabricius (Hymenoptera, Siricidae) em plantios de Pinus patula (Pinaceae) em Minas Gerais, Brasil. Revista Brasileira de Entomologia, v. 51, n. 4, dez., 2007. p. 529-531.

IEDE, E.T.; PENTEADO, S. do R. C. REIS FILHO,W. Uso do nematóide no controle da vespa-da-madeira. Colombo, 2009. 1 fôlder.

KLASMER, P.; BOTTO E. N.;. CORLEY J. C;. VILLACIDE J. M.; FERNÁNDEZ, V. A. 2000. Avances en el control biológico de Sirex noctilio en la región patagónica de la Argentina. Serie técnica IPEF, 13(33): 21-30.

KRONKA, F.J.N.; BERTOLANI, F.; PONCE, R.H.A cultura do Pinus no Brasil. São Paulo: Sociedade Brasileira de Silvicultura, 2005.

MADDEN. J. L. Oviposition behavior of the woodwasp Sirex noctilio F. Australian Journal of Zoology, Melbourne, v. 22, p. 341-351, 1974.

NEUMANN, F. G.; MOREY,J.L.; MCKIMM, R.J.The sirex wasp in Victoria. Victoria: Department of Conservation, Forest and Lands, 1987.41 p. (Bulletin, 29).

NIEFER, I. A., Deslocamento do nematóide Deladenus siricidicola bedding (neotylenchidae) dentro da madeira de Pinus taeda L. em condições de laboratório. 1994.111p. Dissertação (Mestrado em Engenharia Florestal) - Universidade Federal do Paraná, Curitiba, PR.

PENTEADO, S. R. C. Métodos de amostragem para avaliação populacional de Sirex noctilio F., 1793 (Hymenoptera: Siricidae) e de seus inimigos naturais, em Pinus taeda. 1995. 131p. Dissertação (Mestrado em Ciências Biológicas) - Universidade Federal do Paraná, Curitiba, PR.

PENTEADO, S. do R. C.; IEDE, E. T.; REIS FILHO, W. Manual para o controle da vespa-da-madeira em plantio de pinus. Embrapa Florestas. Documentos 76, Colombo - PR. 38p. 2002.

PENTEADO, S. do R. C.; PENTEADO JUNIOR, J. F.; BUHRER, C. de B.; POSANSKI, R. G. Custo de aplicação do inóculo de nematoide, em gelatina e em hidrogel, para o controle da vespa-da-madeira. Comunicado Técnico 341. Colombo - PR. 2014.

PENTEADO, S. do R. C.; IEDE, E. T.; REIS FILHO, W. Manual para o controle da vespada-madeira em plantio de pinus. 2. ed. rev. e atual. Embrapa Florestas. Documentos 76, Colombo - PR. 39p. 2015. 
REBUFFO, S. La_“avispa de la madera” Sirex noctilio F. en el Uruguay. Montevideo: Ministério de Ganaderia, Agricultura y Pesca, Dirección Forestal 1990. 17 p.

RIBAS JUNIOR, U. Práticas de controle da vespa-da-madeira em povoamentos de Pinus do sul do Brasil e efeitos de seu ataque nas propriedades da madeira de Pinus taeda. Serie Técnica IPEF, Piracicaba, v. 9 n. 27, p. 45-57, ago. 1993. Disponível em: $<\underline{\text { http://www. }}$ ipef.br/publicacoes/stecnica/nr27/cap04.pdf $>$. Acesso em: 20 de maio de 2014.

RODIGHERI, H. R.; IEDE, E. T.; PENTEADO, S. R. C; REIS FILHO, W. Avaliação dos Impactos do Programa de Manejo Integrado de Pragas para o Controle da Vespa-daMadeira em Plantios de Pinus no Sul do Brasil. Comunicado Técnico 158. Colombo - PR. 2006.

SANASA. Servicio Nacional de Sanidad y Calidad Agroalimentaria. Avispa barrenadora de los pinos. 2004. Disponível em: $<$ http://www.senasa.gov.ar/contenido. php?to $=n \&$ in $=878 \&$ io $=4716>$. Acesso em: 02 junho 2015.

TAYLOR, K. L. The Sirex woodwasp: ecology and control of an introduced forest insect. In: KITCHING, R. L.; JONES, R. E. The ecology of pests: some Australian case histories. Melbourne: CSIRO, 1981. p. 231-248. 